\title{
Saras Cranes in Palwal District in Southern Haryana are Asking for Immediate Attention for Their Last Rescue Effort
}

Tirshem Kumar Kaushik ${ }^{1^{*}}$, Rohtash Chand Gupta ${ }^{1}$, Parveen Kumar Vats ${ }^{1}$

${ }^{1}$ Department of Zoology, Kurukshetra University, Kurukshetra (136119), Haryana, India

\section{ABSTRACT}

Saras Cranes Grus antigone are endangered birds of open wetlands with highly worrying depletion trends being witnessed related with disappearance of marshy and shallow perennial, expansive wetlands throughout northern India. Alongside, massive hunting in 18th, 19th and 20th centuries and even today is another serious cause for their worrisome deterioration. Also, destruction of nests, eggs, fledglings and adults by aboriginals inde liberately or deliberately is causing these cranes to perish sooner than latter, completely. Now, Saras Cranes are found in limited number and domain as four populations in the entire world including India, China, Burma, South East Asia and northern Australia. The population of Indian Saras Crane is pitiably restricted to Etawa and Mainpuri districts of Uttar Pradesh. Stray birds of this species are restricted to Kanha National Park in Madhya Pradesh and in some parts of Gujarat and Assam. It is interesting to note that few pairs have been seen in Faridabad and Palwal districts in southern Haryana, India. These need to be protected and conserved.

Keywords: conservation efforts, deteriorating trends, Haryana, Palwal District, saras cranes

\section{INTRODUCTION}

Saras cranes are very tall birds (5-6 feet) of open wetlands having a very characteristics red color on its head contiguous portion of neck with somewhat over all grey color [1]. In flight blackish primaries on its wings can be seen in contrast with white ones behind. In contrast to Herons, Saras Cranes hold out their head straight and not withdrawn and curved. In Sanskrit language, Saras Cranes were first named as "Sarasa" which refer to its habitat-Lake Bird. The specific name of antigone has been derived after the daughter of Oedipus who unfortunately hanged herself- perhaps relates to the bare skin feature of the bird's neck. Saras Crane is non-migratory open wetland bird known for perfect marital fidelity having very limited distribution in the world and so also in India. The present study is focused in two districts namely Palwal and Faridabad in southern Haryana.

Saras Cranes were first scientifically named in 1758 by Linnaeus as: Grus antigone and is now better known as Grus antigone antigone. At the same time, it is opined that all three subspecies of Saras Crane in the

\footnotetext{
${ }^{*}$ Corresponding author:

Tirshem Kumar Kaushik

Department of Zoology, Kurukshetra University,

Kurukshetra (136119), Haryana, India

E-mail: tarshemkaushik@rediffmail.com
}

world are facing extreme difficult conditions. The three subspecies of Saras Crane are Indian Saras Crane Grus antigone antigone (Linnaeus, 1758), (2) Indo-Chinese or Burmese Saras Crane Grus antigone sharpii (Blanford, 1895) and (3) Australian Saras Crane Grus antigone gilliae (Schodde, 1988). The Saras Cranes once found in Philippines recently has become extinct: Grus antigone luzonica (Hachisuk 1941). The Indian Saras Crane is extremely limited in its distribution as well as in number. As of now it can be seen in open wetlands in free conditions in Kanpur-Dehat District, Mainpuri, Etawah in Indo-gangetic plains of Uttar Pradesh. It is also found in Bharatpur National Park. In isolated conditions it is found in Gujarat and Assam. Historic account reveals that once upon a time Saras Cranes in India were found between Gangetic plains and Godavari River as also between the entire breadth spanning from Assam to Gujarat. Indian Saras Cranes inhabit open wet and dry grasslands, agricultural fields, marshes and pools [2]. It is pertinent to mention that Saras Crane is increasingly forced to use suboptimal rice paddies as breeding habitat due to the deterioration and destruction of its natural wetland habitat $[10,14]$. The various ornithologists studied the breeding biology of Saras Crane in India [5-7,9$12,15,17,18]$. The present studies focus attention on the miniscule presence of Saras Cranes in Faridabad, 
Palwal and Gurgaon districts of Haryana contiguous Mathura, Aligarh, Bulandshahar and Siddhartha Nagar districts of Uttar Pradesh. The studies certainly prove that even today Saras Cranes are available in very miniscule numbers in Faridabad and Palwal districts.

No definite accounts are available from Haryana's Palwal and Faridabad Districts which are contiguous with Uttar Pradesh, Aligarh, Bulandshar, Mathura etc and Hence the present studies.

\section{MATERIALS AND METHODS}

Haryana state is very diverse in it's terrain and topography despite of it's small area. It is situated between the latitude $30.30^{\circ}$ North and longitude $74.60^{\circ}$ East. The Faridabad and Palwal Districts are actually quite different from typical Haryanivi culture due to their proximity with Uttar Pradesh and similarity of culture with adjoining Brij-Pradesh of Uttar Pradesh. Just because, Saras Cranes are more akin to Etawa and Mainpuri districts of Uttar Pradesh, yet have been sited in very few numbers and limited occasions in Palwal.

It's populations were spread in gangetic plains in the historic times and were subsequently destroyed by a combination of adverse circumstances including depletion of wetlands destruction of nests, eggs and siblings in the recent times. In the colonial British India the staffers of the then Govt. hunted the bird in hundreds and thousands.

The present study was carried out during 2005-

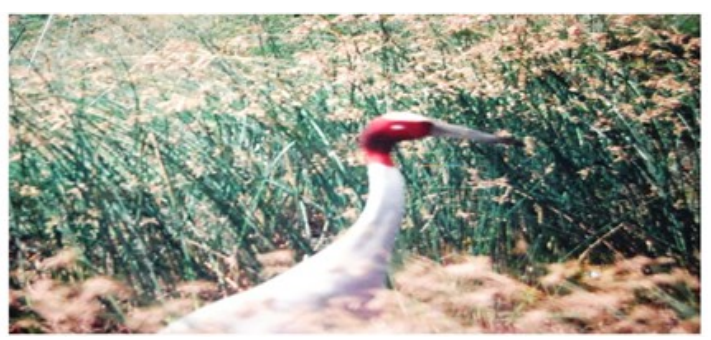

A
2013 in three districts of Haryana namely Palwal $\left(28.15^{\circ} \mathrm{N} 77.33^{\circ} \mathrm{E}\right)$, Faridabad $\left(28.43^{\circ} \mathrm{N} 77.32^{\circ} \mathrm{E}\right)$ and Gurgaon (28.420N 77.020E). Extensive survey was done in the interior of all the three districts with the help of motorcycle. Extensive photography was done with the aid of Nikon P500 Camera. Birds were identified with the help of literature and reference books $[1,4,8]$.

\section{RESULTS AND DISCUSSION}

The present research work has been carried out during 2005-2013 in Faridabad, Gurgaon and Palwal districts of Haryana for the observation of Saras Crane. The Saras Cranes which are highly endangered bird have been spotted in Palwal $\left(28.15^{\circ} \mathrm{N} 77.33^{\circ} \mathrm{E}\right)$ and Faridabad districts $\left(28.43^{\circ} \mathrm{N} 77.32^{\circ} \mathrm{E}\right)$ of Haryana. Faridabad District alongwith Palwal District were a part of Gurgaon upto recently. In Palwal District, Saras Crane is sighted very often, although in just one or two pairs on National Highway No.2. This Highway through leads to Mathura district and is juxtaposed to Aligarh and Bulandshar Districts in the Yamuna bastion. It is pertinent to mention that Saras Cranes has been seen in Palwal towards Hodal and Mathura. It seems that there is a contiguity of Saras cranes connecting the Haryana Saras Cranes of Palwal and Faridabad districts with those of Mainpuri and Kanpur Dehat districts of central Uttar Pradesh. As such, the present studies prove that in a state like Haryana, Saras

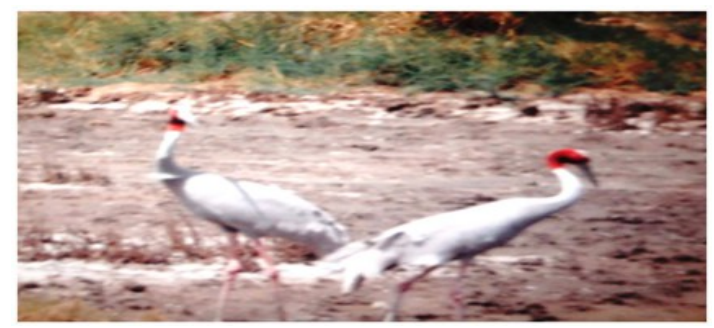

B

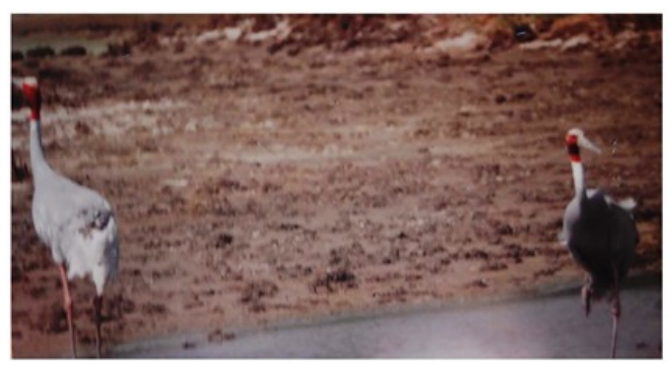

C

Figure 1. Photographic inventory of Saras Cranes Grus antigone observed from: A. Palwal, B. Faridabad, and C. Gurgaon districts in southern Haryana in India. 
cranes are seen, yet in small numbers in Palwal and Faridabad districts.

Saras Crane is listed in the Schedule IV of the Wildlife Protection Act, 1972 [3]. As per IUCN Red Data Book, Saras Crane is vulnerable species [3]. It is listed in Appendix II of CITES (The Convention on international trade in Endangered Species of Wild Fauna and Flora). It is crucial to mention that one pair of Saras Crane was spotted in 2006 in Damdamma wetland near Sohna in Gurgaon district (Figure 1). It was actually seen in February month in wheat fields of Harchandpur village. It was also seen in Gaunchi village near Ballabgarh in fields in 2007. Meanwhile, a pair was spotted in village Kashipur in 2006 near Palwal District. At the same time, one pair of Saras crane was also seen in Junehra village in 2008. It was also seen in village Ahmadpur in year 2008, Gari Begumpur village in 2008 and in Bijopur village in year 2009. As per these studies, it seems its number less than 15-16 in entire Palwal district alongwith Faridabad district. Most serious thing is that Saras Cranes could not be seen atleast in Damdamma Lake in 2011-14 in September and December. Hence it is a cause of worry.

It is pertinent to mention that Etawah and Mainpuri districts of Uttar Pradesh where currently limited surviving populations are still available are not very far off from Palwal. Actually one can say that once upon a time, Saras Cranes were contiguously found in Mainpuri, Etawah, Kanpur Dehat, Bulansahar, Aligarh, Agra, Palwal and Faridabad district in Haryana.

The small population of Saras Cranes is still available in open wetlands in Manipuri and Etawah districts in Uttar Pradesh [16-17]. Vyas [19] reported a total of 278 adult birds from 10 districts of Rajasthan state, out of which 133 birds were in pairs and 12 birds were seen singly.

Ramachandran and Vijayan [13] reported largest flocks of Saras Cranes from Keoladeo National Park in Rajasthan having 430 birds and from wetlands in Etawah and Mainpuri districts in Uttar Pradesh, ranging from 245-412 birds. According to present studies, Saras Cranes (Less than two pairs) have been seen in Palwal and Faridabad districts between 2005-2013 in open wetland like Gonchi, Junhera, Gari Begumpur and Harchandpur village.

Also, 2 pairs of Saras Cranes in the interior of Kanpur-Dehat district in the third week of February 2007. It was also seen in Mathura-Palwal boundary in just pair in April 2007. There is a possibility of some residual populations of Saras Cranes might be existing in Kanpur, Mainpuri, Aligarh and Mathura. These must be surveyed on urgent basis.

\section{CONCLUSIONS}

In conclusion, Haryana Governments' Wildlife Department should on emergent basis, determine the locations of those wetlands, or for that matter, fields harbouring small time perennial ponds where still Saras Cranes are struggling to survive in Hodal, Palwal, Ballabgarh, Faridabad. Hereafter contiguity of Saras presence in rural areas of Jhansi, Aligarh, Gwalior, Hathrus, Hapur, Bareilly belt be established after surveys.

\section{ACKNOWLEDGMENT}

The authors are grateful to authorities of Kurukshetra University including the Chairman, Department of Zoology for support, encouragement and facility for present research work.

\section{REFERENCES}

1. Ali S and Ripley S D (1987) Handbook of the birds of India and Pakistan together with those of Bangladesh, Nepal, Bhutan and Sri Lanka. Oxford University Press. New Delhi. Vols 1-10.

2. Archibald G W, Sundar K S G, Barzen J (2003) A review of the three subspecies of Sarus Cranes Grus antigone. Journal of Ecological Society.16: 5-15.

3. Birdlife International (2014) Species factsheet: Antigone antigone. Downloaded from http://www.birdlife.org on 01/10/2014. Recommended citation for factsheets for more than one species: BirdLife International (2014) IUCN Red List for birds. Downloaded from http://www.birdlife.org on 01/10/2014.

4. Grimmet R, Inskipp T, Inskipp C (1998) Birds of the Indian subcontinent. Oxford University Press. Delhi. 888pp

5. K. Mrutyumjaya Rao (2007) Sighting of Sarus Crane Grus antigone near Telineelapuram, Srikakulam district, Andhra Pradesh. Indian Birds. 3:1.

6. Kandarp Kathju (2007) Observations of unusual clutch size, renesting and egg concealment by Sarus Cranes Grus antigone in Gujarat, India. Forktail. 23: 165-167.

7. Khacher L (2006) The Sarus Crane Grus antigone is on its way out. Indian Birds. 2(6): 168-169.

8. Kumar A, Sati JP, Tak PC, Alfred JRB (2005) Handbook on Indian Wetland Birds and their Conservation. Published by Director, Zool. Surv. India. I-xxvi: 1-468.

9. Lahiri RK (1955) Breeding of Sarus Crane [Antigone a. antigone (Linn.)] in captivity. Journal of the Bombay Natural History Society. 53: 1: 130-131.

10. Meine C D, Archibald G W (1996) The cranes - status survey and conservation action plan. International Union 
for Conservation of Nature and Natural Resources. Gland, Switzerland, and Cambridge, U.K.

11. Menon V (1993) Status of wetland systems in and around Delhi, North India. IWRB Slimbridge. UK. 50.

12. Mukherjee A, Borad C K, Parasharya BM (2002) Breeding performance of the Indian sarus crane in the agricultural landscape of western India. Biological Conservation. 105(2): 263-269.

13. Ramachandran NK, Vijayan VS (1994) Distribution and general ecology of the Sarus Crane (Grus antigone) in Keoladeo National Park, Bharatpur, Rajasthan. J. Bombay Nat. Hist. Soc. 91(2): 211-223.

14. Sundar KSG (2009) Are rice paddies suboptimal breeding habitat for Sarus Cranes in Uttar Pradesh, India?. Condor. 111(4): 611-623.

15. Sundar KSG, Choudhury BC (2001) A note on Sarus
Crane Grus antigone mortality due to collision with hightension power lines. Journal of the Bombay Natural History Society. 98: 108-110.

16. Sundar KSG, Choudhury BC (2003) The Indian Sarus Crane Grus a. antigone: a literature review. Journal of Ecological Society. 16: 16-41.

17. Sundar KSG, Choudhury BC (2005) Mortality of Sarus Cranes (Grus antigone) due to electricity lines in Uttar Pradesh, India. Environmental Conservation. 32: 260-269.

18. Sundar KSG, Kaur J, Choudhury BC (2000) Distribution, demography and conservation status of the Indian Sarus Crane (Grus antigone antigone) in India. Journal of the Bombay Natural History Society. 97(3): 319-339.

19. Vyas R (2002) Status of Sarus Crane Grus antigone antigone in Rajasthan and its ecological requirements. Zoos' Print Journal. 17(2): 691-695. 